OPEN ACCESS

Edited by:

Jinkai Zheng,

Chinese Academy of Agricultural

Sciences (CAAS), China

Reviewed by:

Fang Yuan,

China Agricultural University, China

Fuguo Liu,

Northwest A\&F University, China

*Correspondence:

Yanping Cao

xdxbtbu@126.com

Specialty section:

This article was submitted to

Food Chemistry,

a section of the journal

Frontiers in Nutrition

Received: 17 March 2020 Accepted: 10 November 2020 Published: 15 December 2020

Citation:

Xu D, Zheng B, Che Y, Liu G, Yuan Y,

Wang $S$ and Cao Y (2020) The Stability, Microstructure, and Microrheological Properties of Monascus Pigment Double Emulsions Stabilized by Polyglycero Polyricinoleate and Soybean Protein Isolate. Front. Nutr. 7:543421 doi: 10.3389/fnut.2020.543421

\section{The Stability, Microstructure, and Microrheological Properties of Monascus Pigment Double Emulsions Stabilized by Polyglycerol Polyricinoleate and Soybean Protein Isolate}

\author{
Duoxia Xu, Boyan Zheng, Yixin Che, Guorong Liu, Yingmao Yuan, Shaojia Wang and \\ Yanping Cao*
}

\begin{abstract}
Beijing Advanced Innovation Center for Food Nutrition and Human Health (BTBU), School of Food and Health, Engineering and Technology Research Center of Food Additives, Beijing Higher Institution Engineering Research Center of Food Additives and Ingredients, Beijing Technology \& Business University, Beijing, China
\end{abstract}

Monascus pigment is a natural food pigment and is commonly used for coloring and as antiseptic of cured meat products, confectionery, cakes, and beverages. However, Monascus pigment is sensitive to environmental conditions. The main aim of this study was to investigate the effect of polyglycerol polyricinoleate (PGPR) and soy protein isolate (SPI) on the particle size, zeta potential, physical stability, microstructure, and microrheological properties of Monascus pigment double emulsions. The effects of ionic strength, heating, and freeze thawing treatment on the stabilities of Monascus pigment double emulsions were also characterized. It was found that the optimum PGPR and SPI concentrations for fabricating Monascus pigment double emulsion were 3.6 and 3.0 wt $\%$, respectively. The fabricated Monascus pigment double emulsion was composed of fine particles with narrow and uniform size distributions. Microrheological property results suggested that the elastic characteristic of the Monascus pigment double emulsion was dominated with increasing PGPR and SPI contents. It was mainly due to the increased collision and interaction between the droplets during the movement resulting in force increasing. Monascus pigment double emulsions with $<5 \mathrm{mM} \mathrm{CaCl}_{2}$ prevented calcium to destroy the physical stability of emulsions, while Monascus pigment double emulsions with more than $10 \mathrm{mM} \mathrm{CaCl}_{2}$ formed creaming. After freeze thawing treatment, creaming occurred in Monascus pigment double emulsion. However, it was stable against heating treatment due to heating leading to a dense network structure. It could be contributed to the practical applications of Monascus pigment double emulsions in food products.

Keywords: Monascus pigment, double emulsions, microrheological properties, stability, microstructure 


\section{INTRODUCTION}

In recent years, people are more aware of the importance of health; these findings make natural pigments become more popular as food colorants (1). Monascus pigment is a natural food pigment and is commonly used for coloring and as antiseptic of cured meat products, confectionery, cakes, and beverages (2). Monascus has been proven to have good biological function in various fields, including lowering blood lipids, lowering blood pressure and cholesterol levels, anti-inflammatory and anti-cancer activity, anti-mutation, immunity, anti-depression, prevention of arteriosclerosis, and other biological activities $(3,4)$.

However, Monascus pigment is sensitive to environmental conditions such as heating, basic or acidic $\mathrm{pH}$, light, and oxygen (5). Therefore, its application in food is limited. There are some studies about the stability of Monascus pigment. Vendruscolo et al. (6) reported the thermal stability of natural pigments produced by Monascus ruberin-submerged fermentation. Jian et al. (7) used gum arabic as a stabilizer for improving Monascus pigment water solubility under acidic conditions through the formation of Monascus pigment-gum arabic complexes. It was found that the study of improving the stability of Monascus pigments was limited (8). Little attention has been paid to improve the stability of Monascus pigments by food delivery system.

Water-in-oil-in-water (W/O/W) emulsions are complex liquid dispersion systems known also as double emulsions, in which a water-in-oil emulsion dispersed in a second continuous water phase (9-11). It is reported that double emulsions can be used to protect and control release of bioactive compounds $(12,13)$. Therefore, double emulsions have good prospect in the application of food, pharmacy, and cosmetic fields $(14,15)$. In previous studies, natural pigments such as $\beta$ carotene and curcumin were encapsulated in emulsions for stabilization studies $(16,17)$. In order to improve the properties of food colorants, beetroot betalains have also been encapsulated in $\mathrm{W} / \mathrm{O} / \mathrm{W}$ emulsions, leading to stable pink-colored double emulsions (14). Using the inner water phase of $\mathrm{W} / \mathrm{O} / \mathrm{W}$ emulsions for encapsulation of Monascus pigment could isolate them from the detrimental surrounding aqueous environment; in order to achieve this, a stable formulation needs to be developed.

Therefore, more comprehensive studies are required to fabricate Monascus pigment double emulsions. Hydrophobic emulsifier polyglycerol polyricinoleate (PGPR) and hydrophilic emulsifier soy protein isolate (SPI) have been shown to be effective for the fabrication of $\mathrm{W} / \mathrm{O} / \mathrm{W}$ emulsions for encapsulation of pigment (18). The main aim of this study was to investigate the effect of different concentrations of polyglycerol polyricinoleate (PGPR) and soy protein isolate (SPI) on the physical stability, microstructure, and microrheological properties of Monascus pigment double emulsions. The effects of ionic strength, heating, and freeze thawing treatment on the stability of Monascus pigment double emulsions were also characterized. The present study could demonstrate the potential of $\mathrm{W} / \mathrm{O} / \mathrm{W}$ emulsions as an effective delivery system for the stabilization of Monascus pigment. Ultimately, this work could be contributed to the practical applications of Monascus pigment double emulsions in food products.

\section{MATERIALS AND METHODS}

\section{Materials}

Monascus pigment was obtained from Guangzhou Tianyi Biologic Technology Co., Ltd (Zhanjiang, China). The hydrophilic emulsifier soy protein isolate (SPI, protein $\geq$ $90.0 \mathrm{wt} \%)$ was purchased from Shanghai Yuanye Biologic Technology Co., Ltd (Shanghai, China). The hydrophobic emulsifier polyglycerol polyricinoleate (PGPR) was purchased from Meida Food Co., Ltd (Beijing, China). Soybean oil (China Kerry Grain and Oil Co., Ltd.) was purchased from a local supermarket and used without further purification. All other chemicals were of analytical grade.

\section{Preparation of Monascus Pigment Double Emulsions \\ Preparation of Primary Water-in-Oil (W/O) Emulsion}

Monascus pigment double emulsions were made in a two-step procedure as shown in Figure 1. The primary W/O emulsion was formed with $10 \mathrm{wt} \%$ inner water phase and $90 \mathrm{wt} \%$ oil phase. For the inner water phase, $0.5 \mathrm{wt} \%$ Monascus pigment was dissolved in ultrapure water at $35^{\circ} \mathrm{C}$ for $1 \mathrm{~h}$. The oil phase was prepared by dispersing different concentrations of PGPR in soybean oil and mixed it with a magnetic stirrer at $50^{\circ} \mathrm{C}$ for $2 \mathrm{~h}$. W/O emulsions were prepared with an Ultra-Turrax homogenizer (IKA T25, Germany) at 15,000 rpm for $10 \mathrm{~min}$ at room temperature.

\section{Preparation of Monascus Pigment Double Emulsion}

For the outer water phase, different concentrations of SPI were dispersed in phosphate buffer at $\mathrm{pH} 6.8$ and mixed it with a magnetic stirrer at $50^{\circ} \mathrm{C}$ for $2 \mathrm{~h}$. The Monascus pigment double emulsion consists of $40 \mathrm{wt} \% \mathrm{~W} / \mathrm{O}$ inner emulsion and $60 \mathrm{wt} \%$ aqueous phase. The primary Monascus pigment $\mathrm{W} / \mathrm{O}$ emulsion and the external aqueous phase containing different concentrations of SPI were sheared at $11,000 \mathrm{rpm}$ for $10 \mathrm{~min}$, at room temperature. The coarse emulsions were subsequently homogenized using a homogenizer (GYB30-6S, Donghua factory, Shanghai, China) at an operational pressure of $50 \mathrm{MPa}$ three times, respectively.

In order to investigate the effect of different contents of emulsifiers (PGPR \& SPI) on the fabrication of Monascus pigment $\mathrm{W} / \mathrm{O} / \mathrm{W}$ emulsion, the final double emulsions with different contents of emulsifiers PGPR ranging from 0.9 to 5.4 $\mathrm{wt} \%$ and SPI ranging from 0.15 to $3.0 \mathrm{wt} \%$ were designed.

\section{Addition of Different Contents of $\mathrm{CaCl}_{2}$ in the Monascus Pigment Double Emulsions}

The influence of ionic strength on the Monascus pigment doubleemulsion physical stability was studied. Different concentrations of $\mathrm{CaCl}_{2}$ solution $(0,10,20,40,100 \mathrm{mM})$ were prepared and then mixed with the Monascus pigment double emulsions (3.6 wt\% PGPR and $3.0 \mathrm{wt} \% \mathrm{SPI})$ in a 1:1 ratio (v/v). 

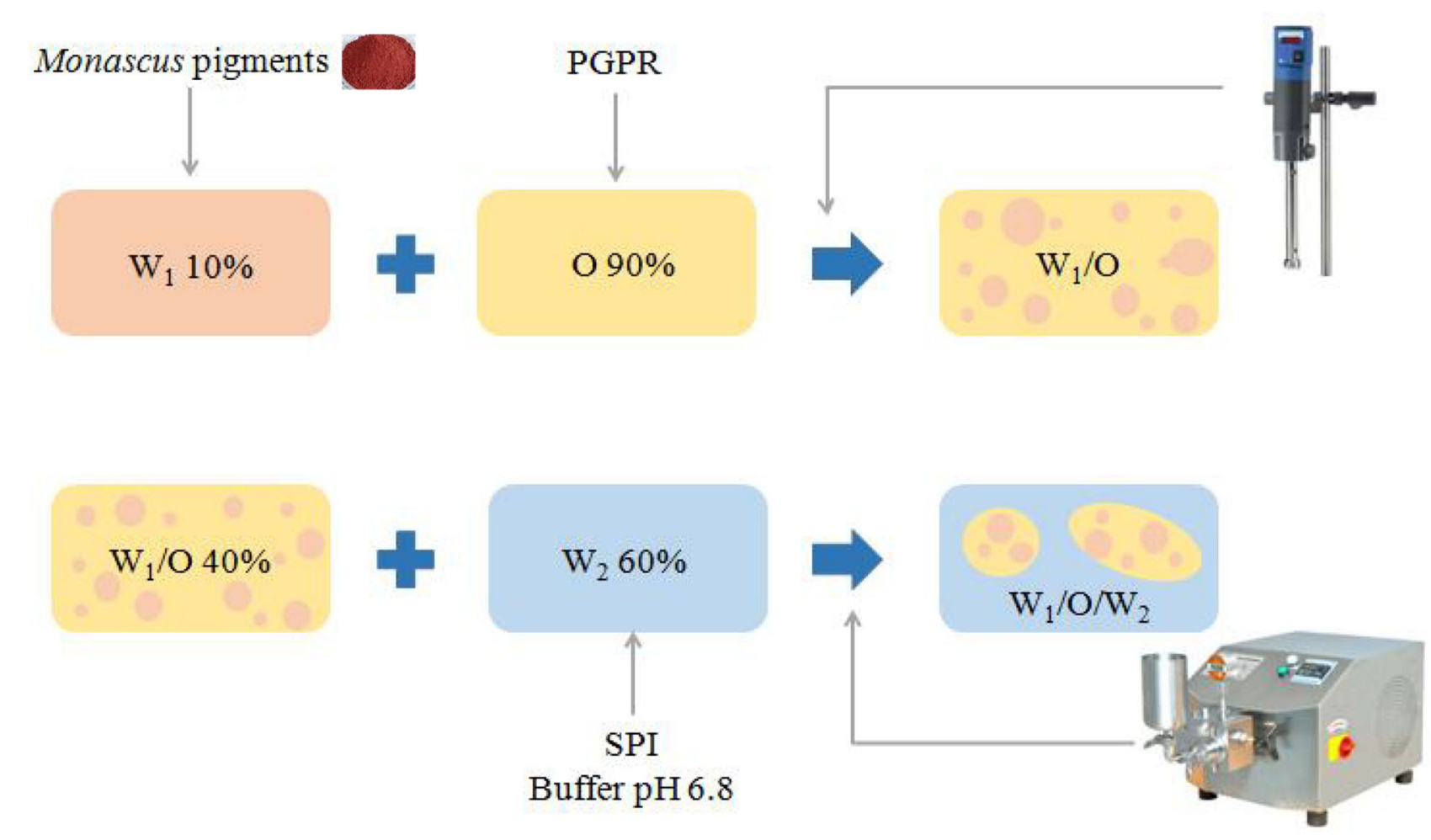

FIGURE 1 | The process of preparing Monascus pigment double emulsions.

\section{Heating and Freeze Thawing Treatments on the Monascus Pigment Double Emulsions}

To investigate the influence of temperature on the stability of Monascus pigment double emulsions, the Monascus pigment double emulsions (3.6 wt\% PGPR and $3.0 \mathrm{wt} \%$ SPI) diluted with phosphate buffer in a $1: 1$ ratio $(\mathrm{v} / \mathrm{v})$ were heated at $90^{\circ} \mathrm{C}$ for $30 \mathrm{~min}$ by thermostat water bath. For the freeze thawing treatment, the Monascus pigment double emulsions were frozen at $-18^{\circ} \mathrm{C}$ for $22 \mathrm{~h}$ then thawed at $40^{\circ} \mathrm{C}$ for $2 \mathrm{~h}$ by thermostat water bath.

\section{Particle Size Measurement}

The average droplet size of Monascus pigment double emulsions was determined according to the method of Wang et al. (19) by dynamic light scattering (DLS) using a Zetasizer Nano-ZS90 (Malvern Instruments, Worcestershire, UK) at a fixed detector angle of $90^{\circ}$. Monascus pigment emulsions were diluted using $1.0 \mathrm{mM}$ phosphate buffer solution at $\mathrm{pH} 6.8$ to minimize multiple scattering effects prior to each measurement. The measured time correlation functions were analyzed by Automatic Program equipped with the correlator. The results were described as mean particle diameter (size, $\mathrm{nm}$ ) and particle size distribution.

\section{Zeta Potential}

The zeta potential of the Monascus pigment double emulsions was measured by using Zetasizer Nano-ZS90 (Malvern Instruments, Worcestershire, UK). The zeta potential was determined by measuring the direction and velocity of droplet movement in the applied electric field. All Monascus pigment double emulsions were diluted 50 times using $1.0 \mathrm{mM}$ phosphate buffer solution at pH 6.8 to avoid multiple scattering effects. After loading the samples into the instrument, they were equilibrated for about $120 \mathrm{~s}$ before particle charge data was collected over 11 continuous readings (20).

\section{Physical Stability Analyzed by LUMisizer}

The physical stability of the Monascus pigment double emulsions with different ratios of SPI and PGPR were measured with the LUMisizer (L.U.M. GmbH, Berlin, Germany), an instrument employing centrifugal sedimentation to accelerate the occurrence of instability phenomena such as flocculation, sedimentation or creaming $(21,22)$. The integration graph shows the percentage of light absorbance per hour described as the "instability index." The physical stability of the Monascus pigment double emulsions can be reflected by the instability index, which is the integrated transmission profile against the measuring time; the higher the instability index, the lower the stability. The instrumental parameters used for the measurement were as follows: volume, $0.4 \mathrm{~mL}$ of dispersion; 2,500 rpm; time, 7,620 s; time interval, $30 \mathrm{~s}$; temperature, $25^{\circ} \mathrm{C}(23)$.

\section{Microstructure}

In this experiment, the microscopic particles of the Monascus pigment double emulsion were directly observed by confocal 
A

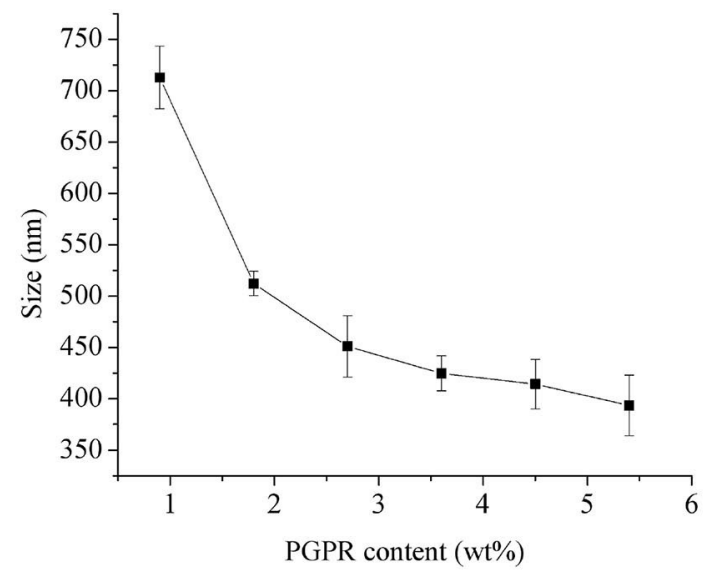

B

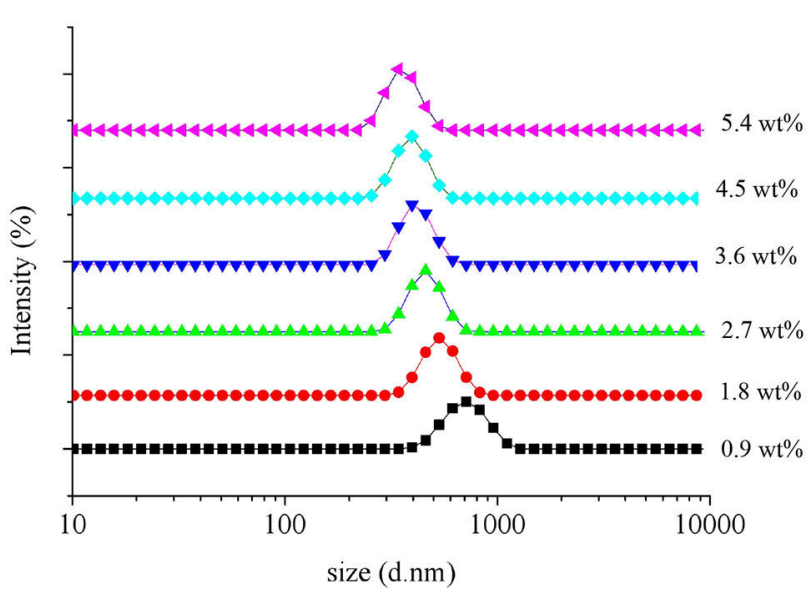

C

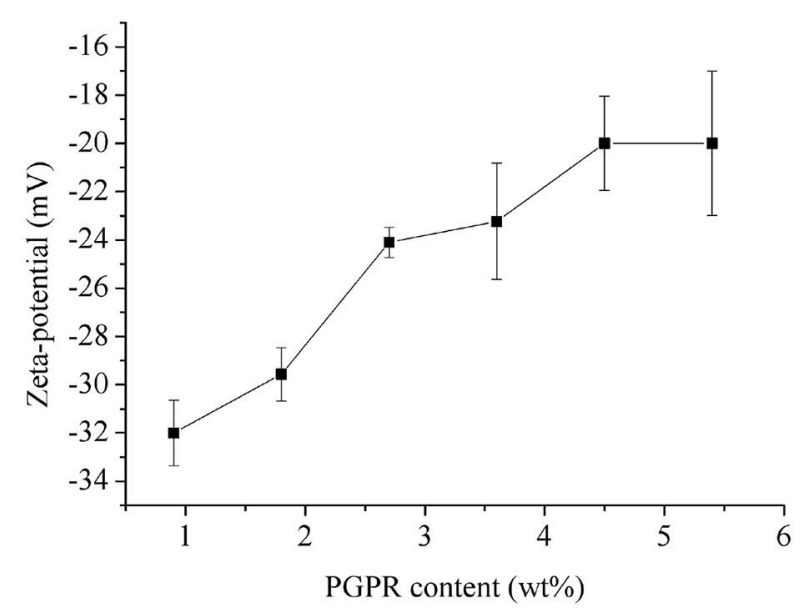

D

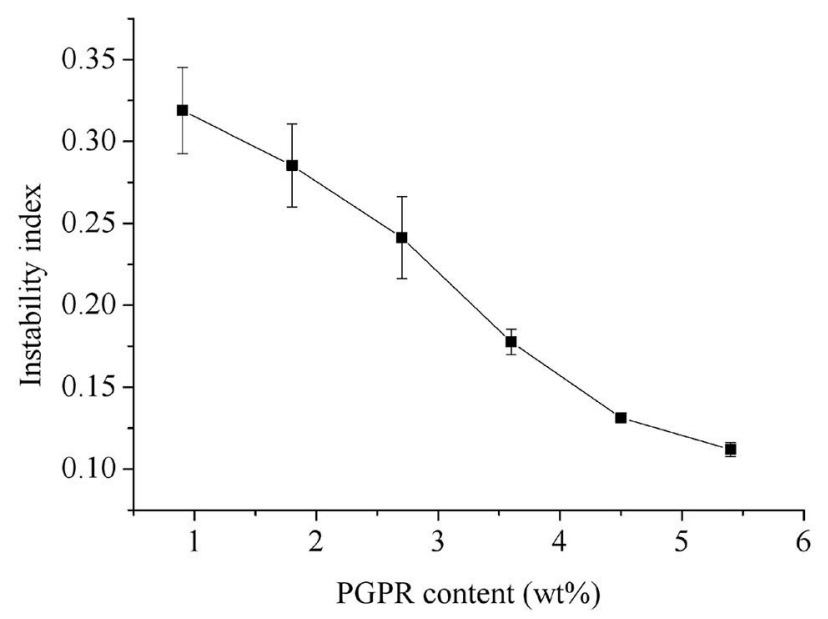

FIGURE 2 | Influence of PGPR concentrations on the mean particle size (A), particle size distribution (B), zeta potential (C), and instability index (D) of Monascus pigment double emulsions.

laser scanning microscopy (FV1200, Olympus, Japan). The SPI in the Monascus pigment double emulsions was dyed with Nile blue at a ratio of $0.025 \%(\mathrm{w} / \mathrm{w})$, and the soybean oil was dyed with Nile red at a ratio of $0.005 \%(\mathrm{w} / \mathrm{w})$. The fluorescence signal from the Nile red and Nile blue dyes was obtained, respectively, by exciting the samples using laser sources of 488 and $637 \mathrm{~nm}$, and collecting wavelengths $590-650 \mathrm{~nm}$ (24). All microstructures were observed with a $60 \times$ objective lens (oil immersion).

\section{Microrheological Property}

The commercial Rheolaser Master (Formulaction, l'Union, France) used for the measurements of the microrheological property of Monascus pigment double emulsions is based on diffusing wave spectroscopy (DWS). The mean square displacement (MSD) curves were calculated from the dynamic speckle images, scattering by the sample as a function of time (25). The Monascus pigment double emulsions was placed into flat-bottomed cylindrical glass tubes $(140 \mathrm{~mm}$ height, $16 \mathrm{~mm}$ diameter). The obtained data were calculated by the software
Rheosoft Master 1.4.0.0 and expressed as solid-liquid balance (SLB) value.

\section{Statistical Analysis}

All Monascus pigment emulsions were prepared in triplicate, and all measurements were performed three times. Data were subjected to analysis of variance (ANOVA) using the software package Origin 8.5 for Windows.

\section{RESULTS AND DISCUSSION}

\section{Effect of PGPR on the Monascus Pigment Double Emulsions}

\section{Particle Size}

The effect of different concentrations of PGPR on the average droplet size of Monascus pigment double emulsion is shown in Figure 2A. There was a significant decrease in the average droplet size from $713.0 \pm 30.7$ to $451.0 \pm 30.0 \mathrm{~nm}$ with increasing amount of PGPR from 0.9 to $2.7 \mathrm{wt} \%$, after which the average 
droplet size decreased from $424.8 \pm 17.1$ to $393.5 \pm 29.6 \mathrm{~nm}$ with the increase of PGPR concentration from 3.6 to $5.4 \mathrm{wt} \%$. The effect can also be seen in the droplet size distributions (Figure 2B). The Monascus pigment double emulsion contained a single peak at each PGPR concentration. The peak shifted to the left and decreased in intensity with increasing PGPR concentrations. For the lower PGPR concentration tested (0.9 and $1.8 \mathrm{wt} \%)$, the Monascus pigment emulsions showed a narrow size distribution, peaks corresponding to bigger sizes. Compared to Monascus pigment double emulsions with $2.7 \mathrm{wt} \%$ PGPR, the sample with $3.6 \mathrm{wt} \%$ PGPR was composed of fine particles with a narrow and uniform size distribution. At higher PGPR concentrations (4.5 and $5.4 \mathrm{wt} \%$ ), the peaks of Monascus pigment emulsions shifted slightly to the left due to the enough adsorbing concentration of PGPR. It was in line with the findings of Marze (26) that slightly higher PGPR concentrations were sufficient for interface coverage $1.2 \mathrm{mg} / \mathrm{m}^{2}$. It has even been reported that larger inner water droplets could lead to the full release of the internal droplet content into the external water phase (27). It was consistent with those previously reported by Hattrem et al. (28) and Serdaroglu et al. (29) for slightly higher PGPR concentrations with good stability of double emulsion.

\section{Zeta Potential}

The effect of different concentrations of PGPR on the zeta potential of Monascus pigment double emulsion is shown in Figure 2C. It was found that the zeta potential of all Monascus pigment double emulsions was negative, indicating the negatively charged emulsions droplets. The zeta potential was obviously affected by the content of PGPR used for emulsification. As shown in Figure 2C, the magnitude of the zeta potential of the Monascus pigment emulsion was decreased gradually from -32.0 to $-20.0 \mathrm{mV}$ with increasing PGPR concentration from 0.9 to $5.4 \mathrm{wt} \%$. This might be explained by the fact that PGPR is a non-ionic surfactant; therefore, a decreased effect on zeta potential was observed by the droplets surrounded by non-ionic surfactants (30). The results suggested that emulsions showed gradual tendency of adsorption with increasing PGPR content.

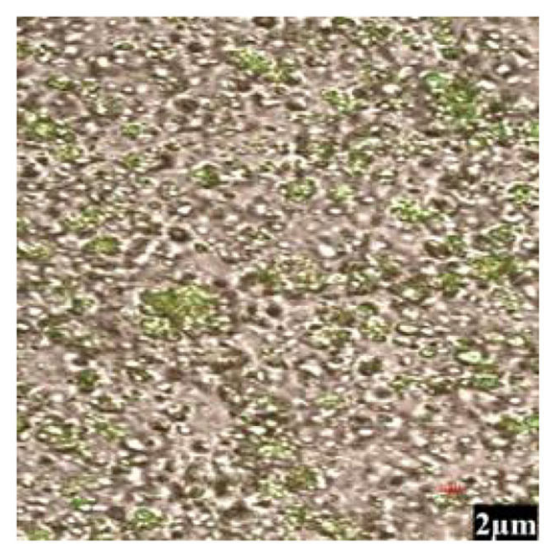

(0.9 wt \% PGPR)

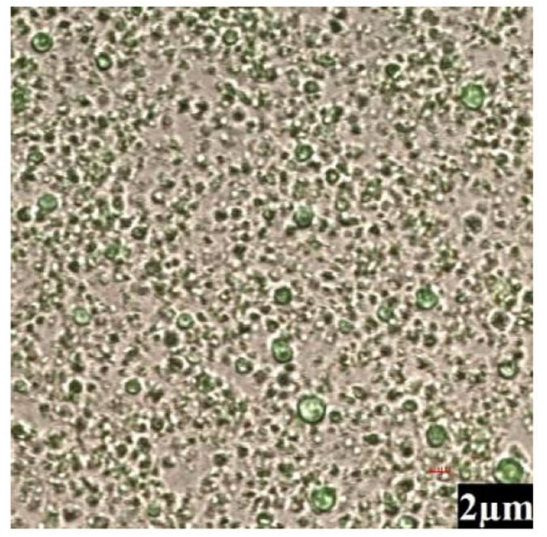

(3.6 wt \% PGPR )

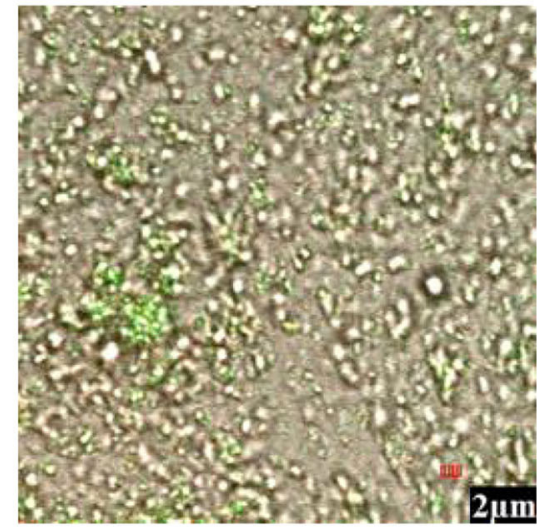

(1.8 wt\% PGPR)

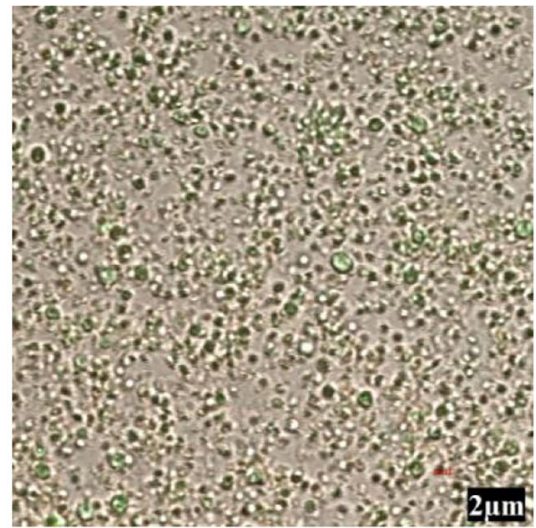

(4.5 wt \% PGPR)

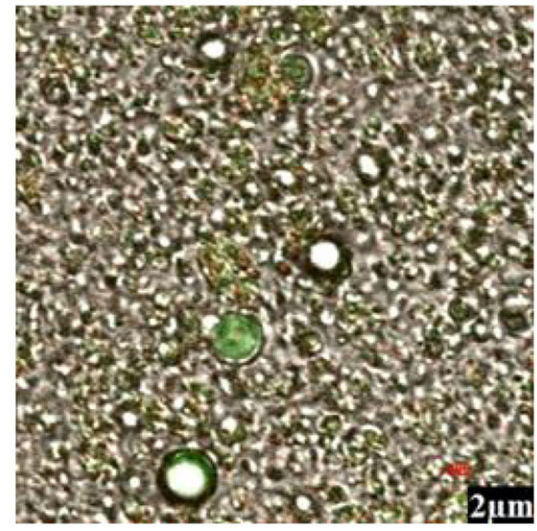

(2.7 wt \% PGPR)

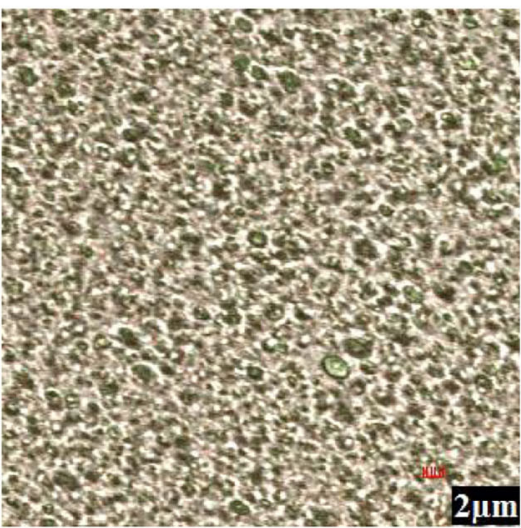

(5.4 wt \% PGPR)

FIGURE 3 | Microscopic images of Monascus pigment double emulsions with different PGPR concentrations. 
It was found that there was no significant difference between zeta potential of emulsions with more than $3.6 \mathrm{wt} \%$ PGPR. It indicated that enough concentration of PGPR for preparing Monascus pigment double emulsion was $3.6 \mathrm{wt} \%$.

\section{Physical Stability}

To further investigate the influence of PGPR concentration on the physical stability of Monascus pigment double emulsions, the instability index was present (Figure 2D). The higher instability index exhibits the much lower stability of the emulsion. As can be seen, the instability index of Monascus pigment double emulsions decreased with increasing PGPR concentration. It demonstrated that preparing Monascus pigment double emulsions with high concentrations of PGPR could enhance the stability. The improved stability of Monascus pigment double emulsions with increasing content of PGPR can be attributed to the strong steric repulsion between droplets resulting from the relatively thick PGPR layer adsorbed to their surfaces. Monascus pigment double emulsions with high concentrations of PGPR had high initial osmotic pressure; a good physical stability could be achieved providing that the PGPR concentration is sufficient (31). On the other hand, the improved stability of the Monascus pigment double emulsions can also be attributed to the increased viscosity and a gel-like network. Similar results were also reported by Cofrades et al. (32) and Serdaroglu et al. (29) who proved that 6.0-6.4 wt\% PGPR in the oil phase was stable on the double emulsions used as animal fat replacers in meat systems.

\section{Microstructure}

Confocal laser microscopy images of Monascus pigment double emulsions with different PGPR concentrations are shown in Figure 3. In the images, the green area represented oil phase enrichment and the red area represented the Monascus pigment phase region. In the microstructure observed by CLSM, Monascus pigment in the out water phase could be seen in the double emulsion with 0.9 wt\% PGPR and some aggregated droplets were shown in the emulsions prepared with $0.9,1.8$, and 2.7 wt\% PGPR. As the PGPR concentration was increased (3.6 and $4.5 \mathrm{wt} \%$ ), aggregated droplets in the microstructure disappeared and small droplets were evenly distributed throughout the emulsion system. It was found that some droplet aggregation was also observed at relatively higher PGPR (5.4 wt\%) concentrations. It can be concluded that the microstructure of Monascus pigment double emulsion stabilized with 3.6 and 4.5 wt\% PGPR was more uniform. According to Eisinaite et al. (31), the water phase was entrapped in the PGPR formed reverse micelles. Therefore, when the content of PGPR was lower, the interfacial tension reduction and the increase of the polarity of the oil phase were not enough to prevent the aggregation of droplets (33). This phenomenon suggests that the presence of enough PGPR could improve the stability of Monascus pigment double emulsion against aggregation and coalescence.

Therefore, 3.6 wt \% PGPR was the optimum concentration for preparing stable Monascus pigment double emulsions. Because

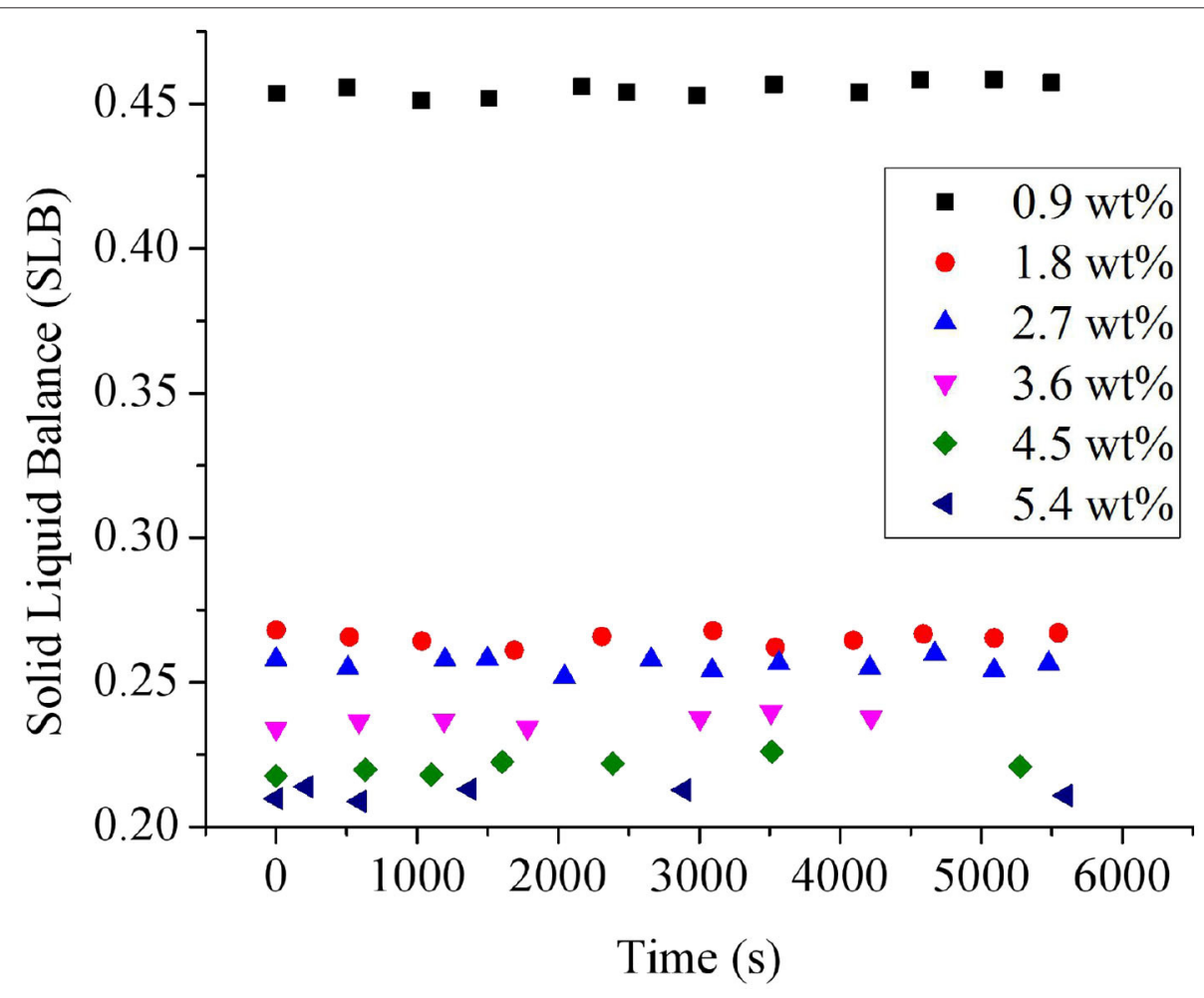

FIGURE 4 | Influence of PGPR concentrations on the solid-liquid balance (SLB) values of Monascus pigment double emulsions. 
the droplets had a relatively smaller droplet size, high zeta potential, and a lower instability index, the Monascus pigment double-emulsion droplets appeared to be saturated with PGPR at this concentration.

\section{Microrheological Properties}

The influence of PGPR concentrations on the microrheological properties of Monascus pigment double emulsions was measured using the Rheolaser lab. The technique monitored the Brownian motion and the interactions of droplets (34). The microrheology study could also illustrate the solid and liquid characteristics of emulsion by solid-liquid Balance (SLB) value, which is a ratio between the solid-like and liquid-like behavior of the sample (23). The droplets' movement showed a more solid behavior when the SLB is $<0.5$, while the emulsion showed a more viscous or liquid behavior with the SLB ranging between 0.5 and 1 (35). As shown in Figure 4, all the SLB values of Monascus pigment double emulsions were $<0.5$, which means that the solid behavior dominated at all the PGPR concentrations. The SLB values of Monascus pigment double emulsions were decreased with increasing PGPR content. It suggested that the elastic characteristic of the Monascus pigment double emulsion was enhanced by the further addition of PGPR. It was mainly due to the increased collision and interaction between the droplets during the movement resulting in force increasing. These results could be explained in terms of a decrease in the mobility of the Monascus pigment double-emulsion droplets with increasing PGPR concentration. It proved that enough PGPR did adsorb to Monascus pigment double-emulsion droplets, leading to a

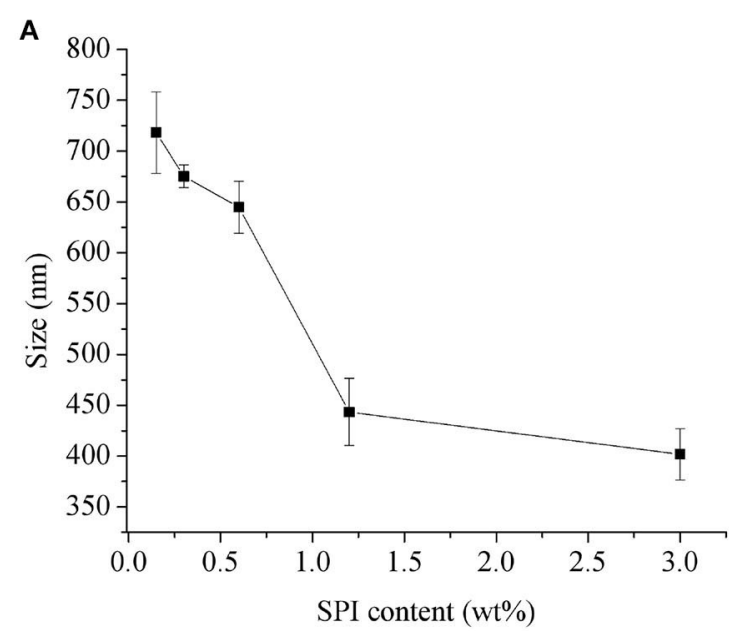

B

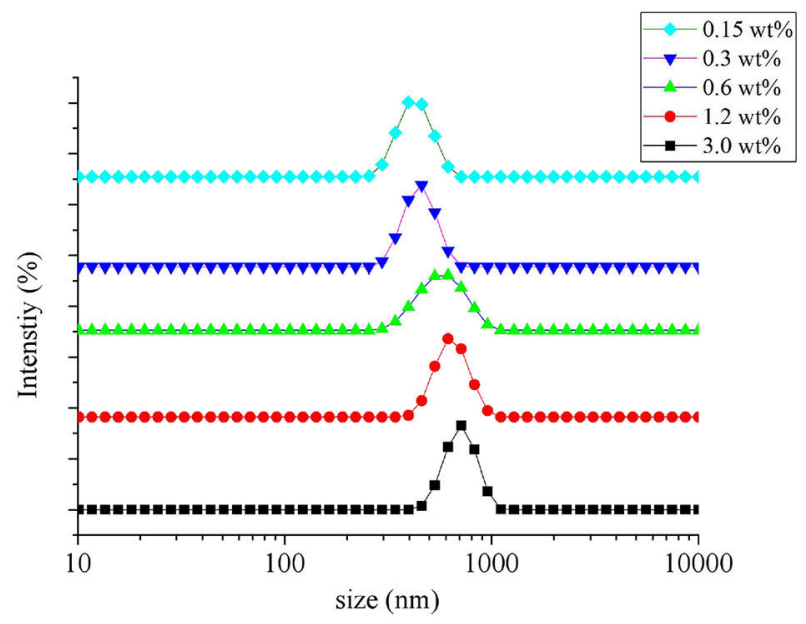

c

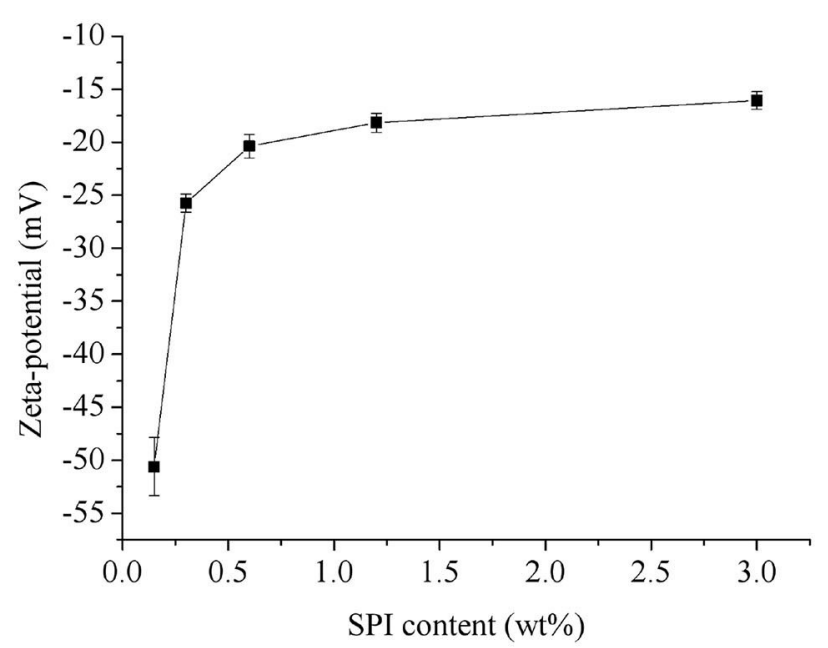

D

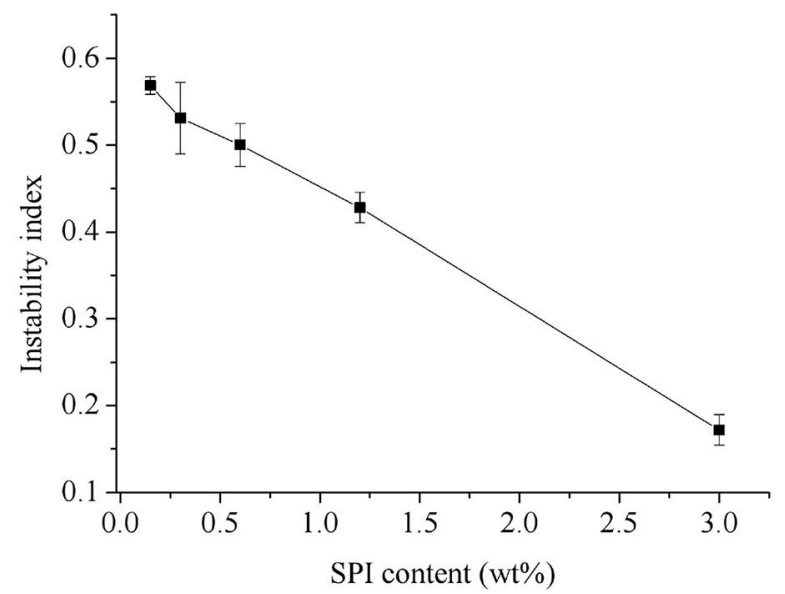

FIGURE 5 | The mean particle size (A), particle size distribution (B), zeta potential (C), and instability index (D) of Monascus pigment double emulsions with different SPI concentrations. 
dramatic decrease of droplet mobility compared with the lower content of PGPR.

\section{Effect of SPI on the Monascus Pigment Double Emulsions}

Particle Size and Zeta Potential

The impact of varied SPI contents on the average droplet size and droplet size distributions of Monascus pigment double emulsion is investigated in Figure 5. It was found that SPI concentration had a strong influence on the droplet size of Monascus pigment emulsion. With increasing SPI concentration, smaller droplets were formed, which is in accordance with conventional emulsification theory (36). The stabilizing effect of emulsifier molecules increases with its concentration. When the SPI concentration was $3.0 \mathrm{wt} \%$, there was a large decrease in the mean particle size. The decrease in droplet size was a clear indication of the enough adsorption of SPI onto the Monascus pigment double-emulsion droplets and corresponded to the differences in the droplet charge described in Figure 5C.
Therefore, SPI as a surfactant was adsorbed to the surface of the droplets forming a protective coating that inhibits droplet aggregation.

Zeta potential, besides size distribution, is another important parameter characterizing stability of emulsion. Figure 5C shows the influence of SPI concentration on the zeta potential of Monascus pigment double emulsions. It was found that the net charge on the Monascus pigment double emulsions became less negative as the SPI was increased. It is generally known that the surface charge of the protein-coated emulsion droplets is governed by the degree of ionization of amino groups $\left(-\mathrm{NH}_{2}\right)$ and carboxyl groups $(-\mathrm{COOH})$ of the protein molecules. The decrease of zeta potential of Monascus pigment double-emulsion droplets with increasing SPI content was attributed to that the structure of interfacial SPI was altered due to its adsorption (37).

\section{Physical Stability}

Monascus pigment double emulsions stabilized with 0.15-3.0 wt\% SPI were examined by the instability index according to the integrated transmission profiles against the measuring time

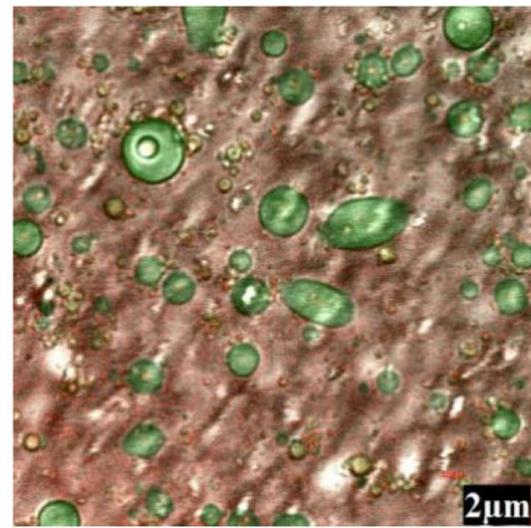

$(0.15 \mathrm{wt} \% \mathrm{SPI})$

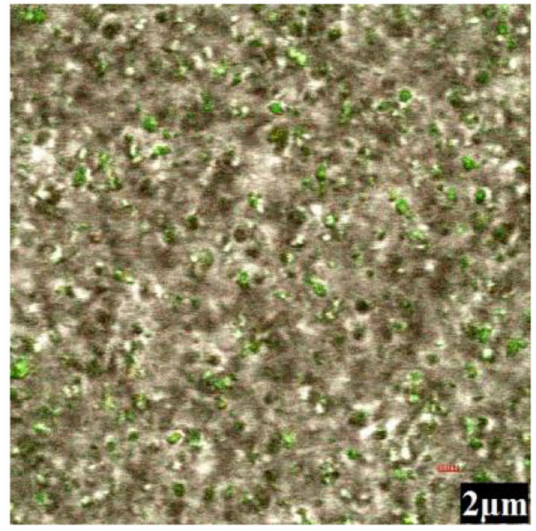

$(1.2 \mathrm{wt} \% \mathrm{SPI})$

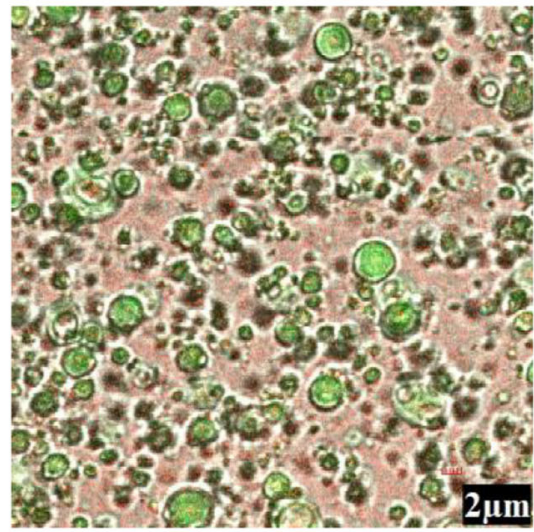

$(0.3 \mathrm{wt} \% \mathrm{SPI})$

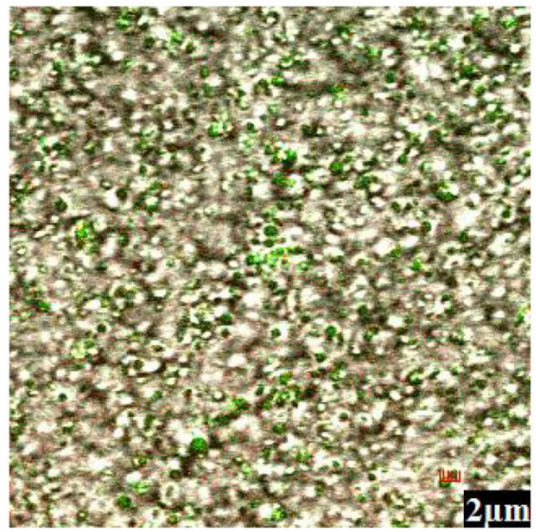

$(3.0 \mathrm{wt} \% \mathrm{SPI})$

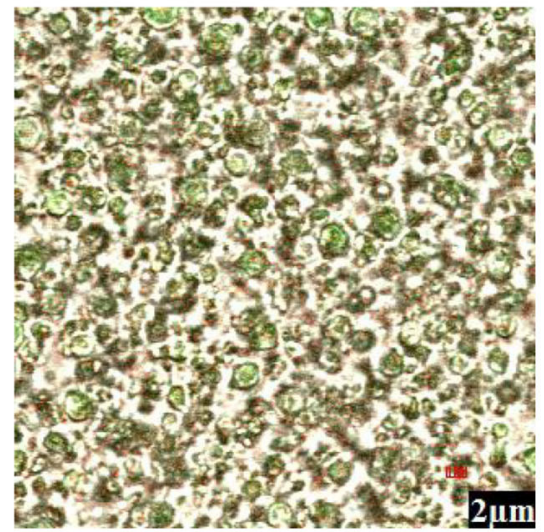

$(0.6 \mathrm{wt} \% \mathrm{SPI})$

FIGURE 6 | Microscopic images of Monascus pigment double emulsions with different SPI concentrations. 


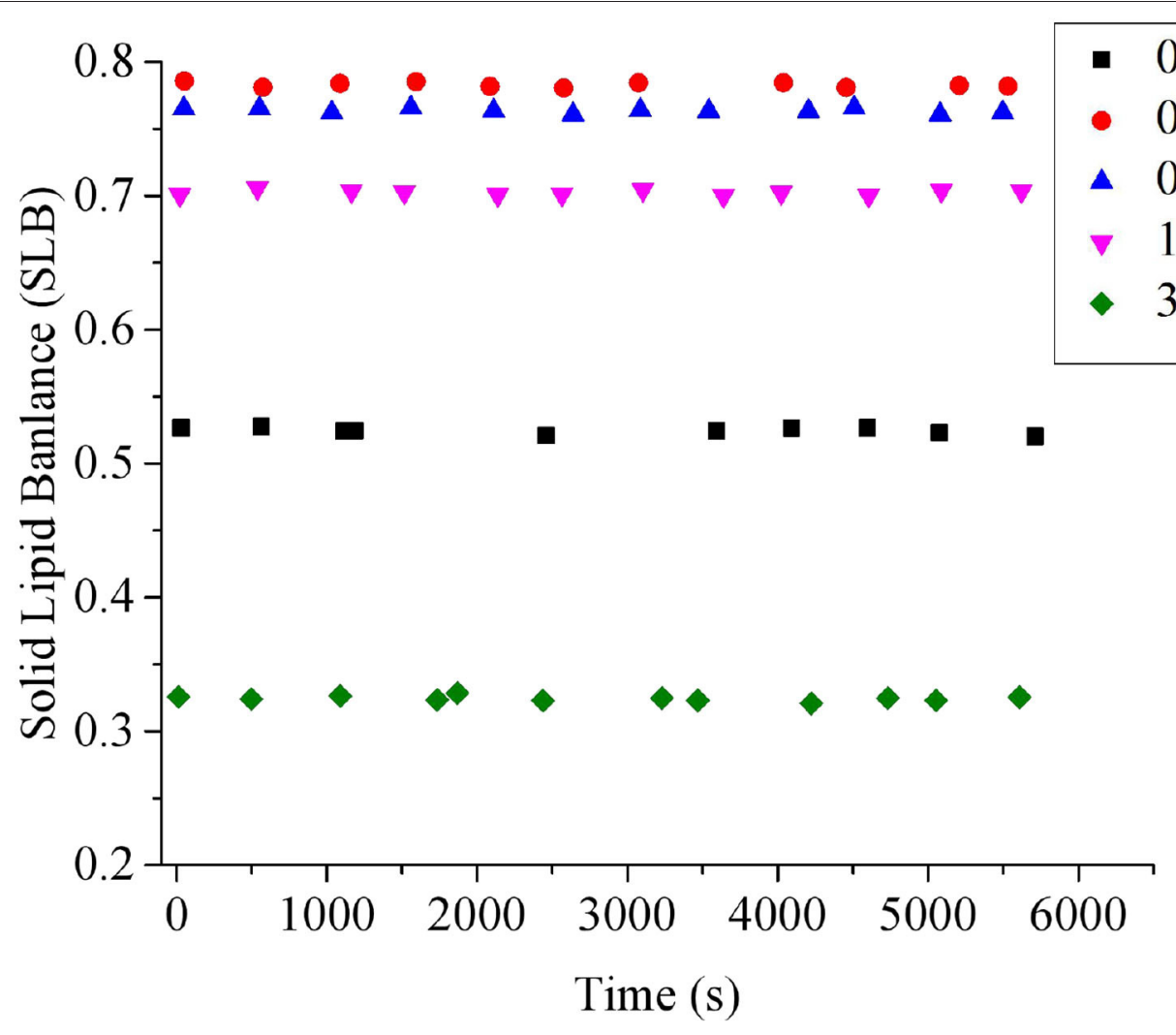

FIGURE 7 | Influence of SPI concentrations on the solid-liquid balance (SLB) values of Monascus pigment double emulsions.

in Figure 5D. As the SPI concentration increased, the instability index decreased, suggesting that SPI can protect the Monascus pigment emulsion from flocculation. The addition of SPI had an optimum effect on the stability for Monascus pigment emulsions with $3.0 \mathrm{wt} \%$ SPI, since the highest SPI concentration led to the lowest instability index. It was reported that the addition of biopolymers to the external phase improved physical stability by forming a coating around droplets or increasing the viscosity (38). The results could be explained by the fact that when the SPI concentration was low, it was insufficient to cover the entire droplet in the emulsion. Thus, it may lead to bridge flocculation by interacting the surfaces of the Monascus pigment double emulsions through attractive electrostatic interaction. With increasing concentration of SPI, it would be enough to cover the droplets and form a thick layer on the Monascus pigment double-emulsion droplets. Therefore, it would inhibit the flocculation by the steric hindrance repulsion.

\section{Microstructure}

The appearance of Monascus pigment double-emulsion droplets was observed by confocal microscopy as shown in Figure 6. The CLSM images confirmed the formation of Monascus pigment double emulsions, which consist of W/O emulsion droplets in the continuous aqueous phase. The oil droplets dyed with Nile red appeared green, the SPI molecules dyed with Nile blue appeared red, and the inner water phase without dye appeared white. When the $\mathrm{W}_{2}$ phase was at low (0.15 and $\left.0.3 \mathrm{wt} \%\right)$ SPI concentration, the double emulsions consisting of relatively large oil droplets without uniform sizes, with some smaller water droplets inside, gave a visual impression of inhomogeneity. The particle size of Monascus pigment double emulsions was decreased with SPI concentration increasing from 0.6 to 3.0 $\mathrm{wt} \%$ leading to the reduction in coalescence of $\mathrm{W} / \mathrm{O}$ emulsion droplets. It may be because SPI exhibit O/W droplets a layer with steric hindrance interaction, as confirmed by the observation of double-emulsion droplets.

\section{Microrheological Properties}

The effect of SPI concentration on the microrheological property of Monascus pigment double emulsion was investigated without disturbing the emulsions system by using the Rheolaser lab. The SLB value indicates the equilibrium state of the emulsion by calculating the slope of the platform area (39). In Figure 7, it was found that the SLB values of the double emulsions were more than 0.5 with SPI $<3.0 \mathrm{wt} \%$, which indicated that those emulsions were liquid behavior, while there was a sharp decrease in SLB value as the SPI concentration was increased to $3.0 \mathrm{wt} \%$. The SLB of Monascus pigment double emulsion stabilized with 3.0 wt $\%$ SPI was $<0.5$. It proved that the Monascus pigment double emulsion with $3.0 \mathrm{wt} \%$ SPI and $3.6 \mathrm{wt} \%$ PGPR presented a solid behavior leading to loss of droplet mobility. This phenomenon 
A

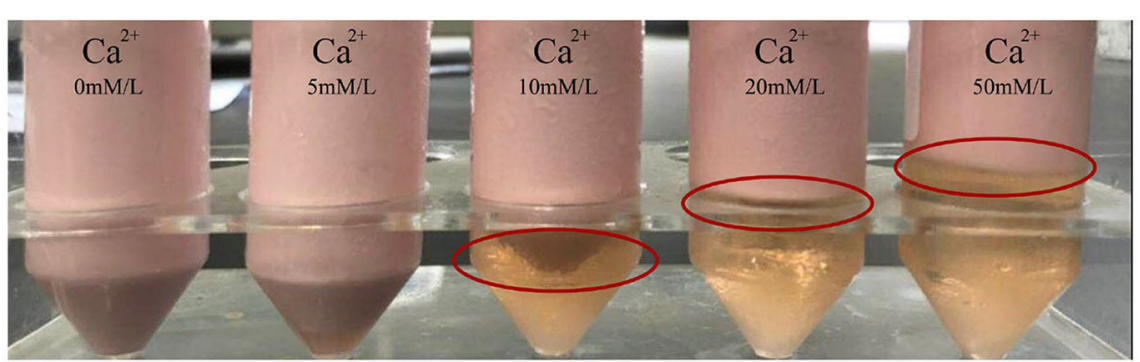

B
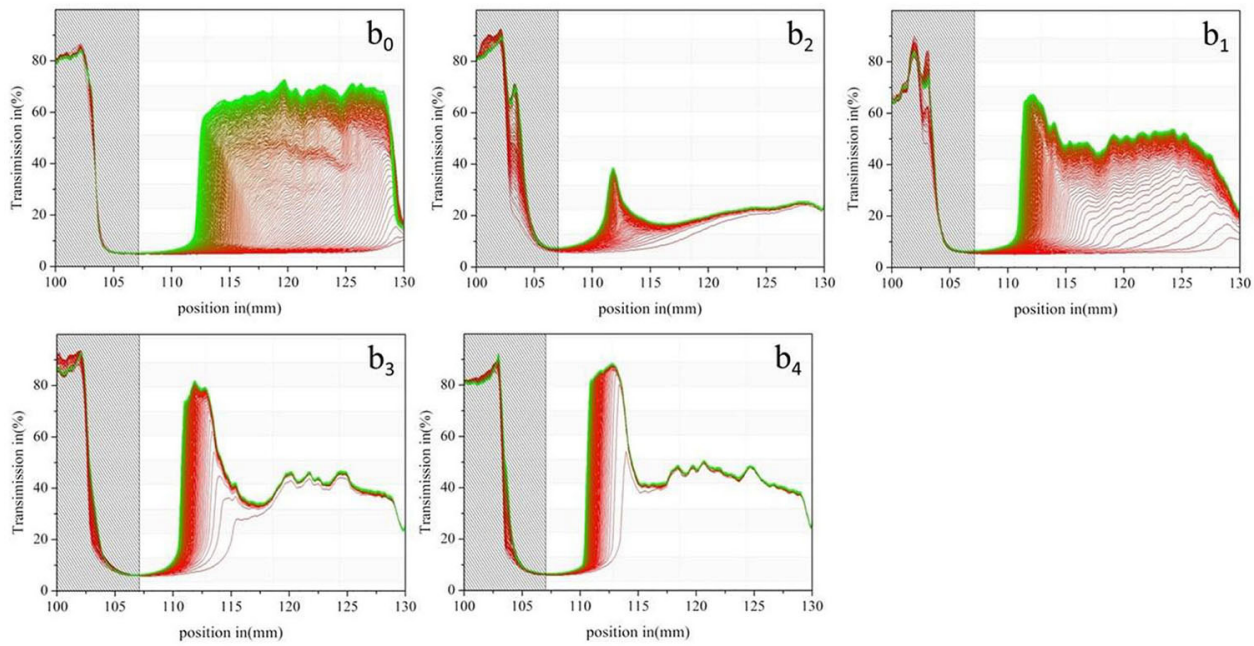

C
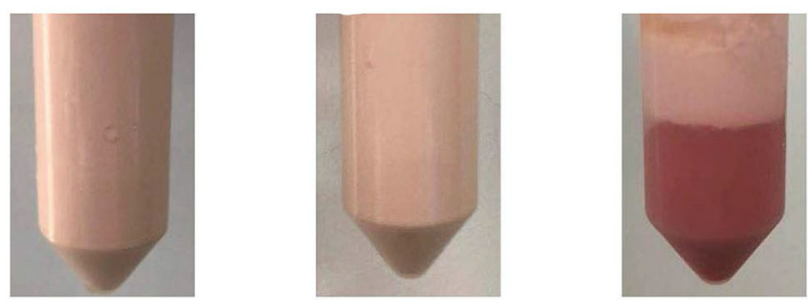

D

Control

After heating

After freeze thawing
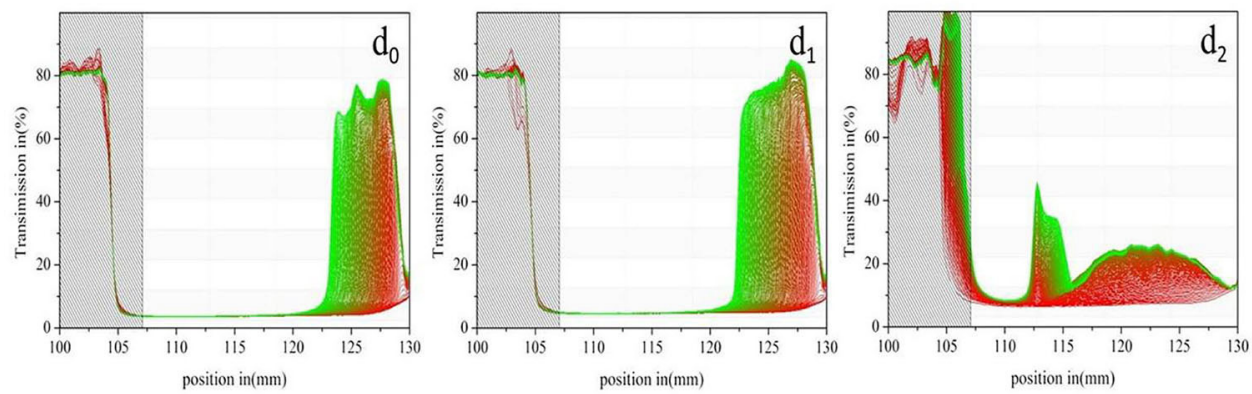

FIGURE 8 | Effect of $\mathrm{CaCl}_{2}$ concentration on the visual creaming stability (A) and the original transmissions as a function of sample position of Monascus pigment double emulsions (B). The stability was expressed as the slope of the integrated transmission time plots determined at $2,500 \mathrm{rpm}$ during $7,650 \mathrm{~s}$ at $25^{\circ} \mathrm{C}\left(\mathrm{b}_{0}\right.$ : without $\mathrm{CaCl}_{2} ; \mathrm{b}_{1}$ : with $5 \mathrm{mM} \mathrm{CaCl} ; \mathrm{b}_{2}$ : with $10 \mathrm{mM} \mathrm{CaCl}_{2}$; $\mathrm{b}_{3}$ : with $20 \mathrm{mM} \mathrm{CaCl}_{2} ; \mathrm{b}_{4}$ : with $50 \mathrm{mM} \mathrm{CaCl}_{2}$. Effect of heating and freeze thawing treatment on the visual creaming stability (C) and original transmissions as a function of sample position (D) of Monascus pigment double emulsions ( $d_{0}$ : control; $d_{1}$ : after thermal treatment; $\mathrm{d}_{2}$ : after freeze thawing treatment). 
may be attributed to the colloidalization of the emulsion system as the SPI concentration was increased to a specific degree.

\section{Effect of lonic Strength, Heating, and Freeze Thawing Treatments on the Stability of Monascus Pigment Double Emulsion}

Figure 8A shows the impact of different $\mathrm{CaCl}_{2}$ concentrations on the visual creaming stability and original transmissions as a function of the sample position of Monascus pigment double emulsions. According to the visual creaming stability, the increase of $\mathrm{Ca}^{2+}$ content in the systems produced a higher extent of creaming. It exhibited that Monascus pigment double emulsions with $<5 \mathrm{mM} \mathrm{CaCl} 2$ prevented calcium to destroy the physical stability of emulsions, while Monascus pigment double emulsions with more than $10 \mathrm{mM}$ calcium concentration were unstable.

The changes in the transmission profiles over space and time further prove that the influence of different $\mathrm{Ca}^{2+}$ concentrations on Monascus pigment double emulsions resulted in different physical stabilities. In Figure 8B, it was found that with increasing $\mathrm{Ca}^{2+}$ concentrations from 5 to $50 \mathrm{mM}$, the first profile taken after $30 \mathrm{~s}$ exhibited high transmissions along the sample length. A sharp front of Monascus pigment double emulsions with more than $10 \mathrm{mM}$ moved toward the top during centrifugation. Our research group (40) reported that the sharp front means that nearly all droplets are moving as a zone creaming. The structure of the creaming was a flocculated network. With increasing concentration of the $\mathrm{Ca}^{2+}$ concentration more than $10 \mathrm{mM}$, the profiles were nearly spaced with a considerably smaller distance during centrifugation. It indicated that these Monascus pigment double emulsions with more than $10 \mathrm{mM} \mathrm{Ca}^{2+}$ were creaming easily. The profiles of Monascus pigment double emulsions with 20 and $50 \mathrm{mM} \mathrm{Ca}^{2+}$ were quite similar. This result can be explained by the binding of SPI by $\mathrm{Ca}^{2+}$, leading to the aggregation by electrostatic screening (41). It was reported that $\mathrm{Ca}^{2+}$ not only contributed its nutritional property but also acted functionally by allowing the obtaining of double-emulsion systems with creamy texture without the need of addition of saturated fats. The obtained result proved that the isolated creaming Monascus pigment double emulsions could work as a reduced fat replacer of whipped dairy cream with important calcium contribution.

The impact of heating and freeze thawing treatment on the Monascus pigment double emulsion was also studied. As shown in Figures 8C,D, it was found that there was no creaming and the Monascus pigment double emulsion was stable against heating treatment. During heating, the bonds between SPI molecules were formed. Presumably, hydrophobic interactions and disulfide bridges often play major roles (42). Hydrogen bonds may also be present. Roesch and Corredig (43) reported that covalent interactions have occurred between soybean proteins during heating. Therefore, heating could result in the improved viscosity of Monascus pigment double emulsion, which led to a more structured network.

After freeze thawing cycling, creaming occurred in Monascus pigment double emulsion. It indicated that the droplets migrated to the top of the sample and promoted their coalescence. It revealed that droplet aggregation and coalescence of Monascus pigment double emulsion occurred after freeze thawing treatments. The destabilization was attributed to the SPI relatively thin absorbed layers of the Monascus pigment doubleemulsion droplets. It also might be because the adsorbed SPI either underwent a conformational change or is desorbed from the droplet surfaces due to freeze-thawing treatments (44).

\section{CONCLUSION}

Monascus pigment double emulsions were fabricated in the presence of PGPR and SPI and characterized in terms of droplet size, stability, microstructure, and microrheological properties. According to the results, the droplet size as well as stability was highly dependent on the concentration of the PGPR and SPI used. Higher PGPR and SPI concentrations yielded lower droplet sizes and higher stability and more solid behaviors. It was shown that $3.6 \mathrm{wt} \%$ PGPR and 3.0 wt\% SPI were the optimum concentrations of emulsifiers to form Monascus pigment double emulsion. Microstructure proved that aggregated droplets disappeared and small droplets were evenly distributed throughout the emulsion system with increasing PGPR and SPI contents. The elastic characteristic of the Monascus pigment double emulsion was enhanced by the addition of PGPR and SPI due to the increased collision and interaction between the droplets. Monascus pigment double emulsion was unstable to more than $10 \mathrm{mM} \mathrm{Ca}^{2+}$ and freezethawing treatment due to the weak electrostatic interaction. However, it was stable against heating treatment probably due to heating leading to a more structured network. It could be useful for a broad application of Monascus pigment double emulsions in food products.

\section{DATA AVAILABILITY STATEMENT}

All datasets generated for this study are included in the article/supplementary material.

\section{AUTHOR CONTRIBUTIONS}

DX, BZ, and YC: data curation, writing-original draft preparation, investigation, and validation. GL, YY, and SW: methodology, investigation, and validation. DX: writing-review and editing, project administration, and funding acquisition. YC: conceptualization, supervision, project administration, and funding acquisition. All authors contributed to the article and approved the submitted version.

\section{FUNDING}

This research was funded by the 13th Five-Year the State Key Development Program (2016YFD0400802), National Natural Science Foundation of China (31771976 \& 32072216), School Level Cultivation Fund of Beijing Technology and Business University for Distinguished 
and Excellent Young Scholars (BTBUYP2020), Beijing Key Laboratory of the Innovative Development of Functional Staple and the Nutritional Intervention for Chronic Disease, Beijing Science and Technology Commission (Z171100001317004), Support Project of High-level Teachers in Beijing Municipal Universities in the Period of 13th Five-year Plan (CIT \& TCD201804018), Construction of Service Capability of Scientific and Technological Innovation

\section{REFERENCES}

1. Downham A, Collins P. Coloring our foods in the last and next millenium. Int J Food Sci Tech. (2000) 35:5-22. doi: 10.1046/j.1365-2621.2000.00373.x

2. Chen W, He Y, Zhou Y, Shao Y, Feng Y, Li M, et al. Edible Filamentous fungi from the species Monascus: early traditional fermentations, modern molecular biology, and future genomics. Compr Rev Food Sci F. (2015) 14:555-67. doi: 10.1111/1541-4337.12145

3. Hsu WH, Lee BH, Liao TH, Hsu YW, Pan TM. Monascus-fermented metabolite monascin suppresses inflammation via PPAR-gamma regulation and JNK inactivation in THP-1 monocytes. Food Chem Toxicol. (2012) 50:1178-86. doi: 10.1016/j.fct.2012.02.029

4. Tseng Y, Yang J, Chang H, Lee Y, Mau J. Antioxidant properties of methanolic extracts from monascal adlay. Food Chem. (2006) 97:375-81. doi: 10.1016/j.foodchem.2005.04.022

5. Singh N, Goel G, Singh N, Pathak BK, Kaushik D. Modeling the red pigment production by Monascus purpureus MTCC 369 by Artificial Neural Network using rice water based medium. Food Biosci. (2015) 11:17-22. doi: 10.1016/j.fbio.2015.04.001

6. Vendruscolo F, Müller BL, Moritz DE, de Oliveira D, Schmidell W, Ninow JL. Thermal stability of natural pigments produced by Monascus ruber in submerged fermentation. Biocatal Agric Biotechnol. (2013) 2:278-84. doi: 10.1016/j.bcab.2013.03.008

7. Jian W, Sun Y, Wu JY. Improving the water solubility of Monascus pigments under acidic conditions with gum arabic. J Sci Food Agr. (2017) 97:2926-33 doi: $10.1002 /$ jsfa. 8130

8. Gandía-Herrero F, Jiménez-Atiénzar M, Cabanes J, García-Carmona F, Escribano J. Stabilization of the bioactive pigment of opuntia fruits through maltodextrin encapsulation. J Agr Food Chem. (2010) 58:10646-52. doi: $10.1021 /$ jf101695f

9. Artiga-Artigas M, Molet-Rodríguez A, Salvia-Trujillo L, Martín-Belloso O. Formation of double (W1/O/W2) emulsions as carriers of hydrophilic and lipophilic active compounds. Food Bioprocess Tech. (2019) 12:422-35. doi: 10.1007/s11947-018-2221-3

10. Dickinson E. Double emulsions stabilized by food biopolymers. Food Biophys. (2011) 6:1-11. doi: 10.1007/s11483-010-9188-6

11. Giroux H, Robitaille G, Britten M. Controlled release of casein-derived peptides in the gastrointestinal environment by encapsulation in water-inoil-in-water double emulsions. LWT-Food Sci Technol. (2016) 69:225-32. doi: 10.1016/j.lwt.2016.01.050

12. Eisinaite V, Juraite D, Schroen K, Leskauskaite D. Preparation of stable food-grade double emulsions with a hybrid premix membrane emulsification system. Food Chem. (2016) 206:59-66. doi: 10.1016/j.foodchem.2016.03.046

13. Lamba H, Sathish K, Sabikhi L. Double emulsions: emerging delivery system for plant bioactives. Food Bioprocess Tech. (2015) 8:709-28. doi: 10.1007/s11947-014-1468-6

14. Eisinaite V, Juraite D, Schroën K, Leskauskaite D. Food-grade double emulsions as effective fat replacers in meat systems. J Food Eng. (2017) 213:54-9. doi: 10.1016/j.jfoodeng.2017.05.022

15. Lobato-Calleros C, Recillas-Mota MT, Espinosa-Solares T, Alvarez-Ramirez J, Vernon-Carter EJ. Microstructural and rheological properties of low-fat stirred yoghurts made with skim milk and multiple emulsions. J Texture Stud. (2009) 40:657-75. doi: 10.1111/j.1745-4603.2009.00204.x

16. Aditya NP, Aditya S, Yang HJ, Kim HW, Park SO, Lee J, et al. Curcumin and catechin co-loaded water-in-oil-in-water emulsion and its
(PXM2019_014213_000010, PXM2018_014213_000033，PXM 2018_014213_000014, 19005857058), Cultivation and Development of Innovation Base Z171100002217019), and Quality Construction of Talents Training-First-class Specialty Construction (Municipal Level), - Food Science and Engineering (PXM2019_014213_000010). The authors are grateful to Guangdong Tianyi Biological Technology Co. for providing the Monascus pigment.

beverage application. J Funct Foods. (2015) 15:35-43. doi: 10.1016/j.jff.2015. 03.013

17. Akinosho HO, Wicker L. Stability of $\beta$-carotene loaded emulsions vary by viscosity of hydroxypropyl methylcellulose dispersions. LWT-Food Sci Technol. (2015) 63:582-9. doi: 10.1016/j.lwt.2015.02.024

18. Utama DT, Jeong H, Kim J, Lee SK. Formula optimization of a Perillacanola oil $(\mathrm{O} / \mathrm{W})$ emulsion and its potential application as an animal fat replacer in meat emulsion. Korean J Food ScI An. (2018) 3:580-92. doi: 10.5851/kosfa.2018.38.3.580

19. Wang $\mathrm{X}, \mathrm{Li} \mathrm{X}, \mathrm{Xu} \mathrm{D}$, Zhu Y, Cao Y, Wang J, et al. Comparision of heteroaggregation, layer-by-layer and directly mixing techniques on the physical properties and in vitro digestion of emulsions. Food Hydrocolloid. (2019) 95:228-37. doi: 10.1016/j.foodhyd.2019. 04.034

20. Wang X, Li X, Xu D, Zhu Y, Cao Y, Li X, et al. Modulation of stability rheological properties, and microstructure of heteroaggregated emulsion: influence of oil content. LWT-Food Sci Technol. (2019) 109:457-66. doi: 10.1016/j.lwt.2019.04.031

21. Ma N, Gao Q, Li X, Xu D, Yuan Y, Cao Y. Enhancing physicochemical stability and digestibility of DHA emulsions by encapsulation of DHA droplets in caseinate/alginate honeycomb-shaped microparticles. Food Funct. (2020) 11:2080-93. doi: 10.1039/C9FO02947H

22. Sobisch T, Lerche D. Thickener performance traced by multisample analytical centrifugation. Colloids Surface A. (2008) 331:114-8. doi: 10.1016/j.colsurfa.2008.05.040

23. Wang $\mathrm{X}, \mathrm{Li} \mathrm{X}, \mathrm{Xu} \mathrm{D}$, Liu $\mathrm{G}$, Xiao J, Cao $\mathrm{Y}$, et al. Influence of unadsorbed emulsifiers on the rheological properties and structure of heteroaggregate of whey protein isolate (WPI) coated droplets and flaxseed gum (FG) coated droplets. Food Hydrocolloid. (2018) 80:42-52. doi: 10.1016/j.foodhyd.2018.01.041

24. Zhang Y, Liang S, Zhang J, Chi Y, Tian B, Li L, et al. Preparation of whey protein isolate nanofibrils by microwave heating and its application as carriers of lipophilic bioactive substances. LWT-Food Sci Technol. (2020) 125:109123. doi: 10.1016/j.lwt.2020.109213

25. Xu D, Qi Y, Wang X, Li X, Wang S, Cao Y, et al. The influence of flaxseed gum on the microrheological property and physicochemical stability of whey protein stabilized $\beta$-carotene emulsion. Food Funct. (2017) 8:415-23. doi: $10.1039 / \mathrm{C} 6 \mathrm{FO} 01357 \mathrm{~K}$

26. Marze S. Relaxation processes of PGPR at the water/oil interface inferred by oscillatory or transient viscoelasticity measurements. Langmuir. (2009) 25:12066-72. doi: 10.1021/la9016849

27. Matsumoto S, Kohda M. The viscosity of W/O/W emulsions: an attempt to estimate the water permeation coefficient of the oil layer from the viscosity changes in diluted systems on aging under osmotic pressure gradients. $J$ Colloid Interf Sci. (1980) 73:13-20. doi: 10.1016/0021-9797(80)90115-0

28. Hattrem MN, Dille MJ, Seternes T, Draget KI. Macro - vs. micromolecular stabilisation of W/O/W-emulsions. Food Hydrocolloid. (2014) 37:77-85. doi: 10.1016/j.foodhyd.2013.10.024

29. Serdaroglu M, Ozturk B, Urgu M. Emulsion characteristics, chemical and textural properties of meat systems produced with double emulsions as beef fat replacers. Meat Sci. (2016) 117:187-95. doi: 10.1016/j.meatsci.2016. 03.012

30. Tamnak S, Mirhosseini H, Tan CP, Amid TB, Kazemi M, Hedayatnia S. Encapsulation properties, release behavior and physicochemical characteristics of water-in-oil-in-water $(\mathrm{W} / \mathrm{O} / \mathrm{W})$ emulsion stabilized 
with pectin-pea protein isolate conjugate and Tween 80. Food Hydrocolloid. (2016) 61:599-608. doi: 10.1016/j.foodhyd.2016.06.023

31. Eisinaite V, Estrada PD, Schroen K, Berton-Carabin C, Leskauskaite D. Tayloring $\mathrm{W} / \mathrm{O} / \mathrm{W}$ emulsion composition for effective encapsulation: the role of PGPR in water transfer-induced swelling. Food Res Int. (2018) 106:722-8. doi: 10.1016/j.foodres.2018.01.042

32. Cofrades S, Antoniou I, Solas MT, Herrero AM, Jimenez-Colmenero F. Preparation and impact of multiple (water-in-oil-in-water) emulsions in meat systems. Food Chem. (2013) 141:338-46. doi: 10.1016/j.foodchem.2013. 02.097

33. Wen L, Papadopoulos KD. Effects of surfactants on water transport in W1/O/W2 emulsions. Langmuir. (2000) 16:7612-7. doi: 10.1021/la00 $0071 \mathrm{~b}$

34. Corredig M, Alexander M. Food emulsions studied by DWS: recent advances. Trends Food Sci Tech. (2008) 19:67-75. doi: 10.1016/j.tifs.2007.07.014

35. Moschakis T. Microrheology and particle tracking in food gels and emulsions. Curr Opin Colloid In. (2013) 18:311-23. doi: 10.1016/j.cocis.2013. 04.011

36. McClements DJ, Decker EA, Park Y, Weiss J. Structural design principles for delivery of bioactive components in nutraceuticals and functional foods. Crit. Rev Food Sci. (2009) 49:577-606. doi: 10.1080/10408390902841529

37. Laouini A, Jaafar-Maalej C, Sfar S, Charcosset C, Fessi H. Liposome preparation using a hollow fiber membrane contactor-application to spironolactone encapsulation. Int J Pharmaceut. (2011) 415:53-61. doi: 10.1016/j.ijpharm.2011.05.034

38. Panagopoulou E, Evageliou V, Kopsahelis N, Ladakis D, Koutinas A, Mandala I. Stability of double emulsions with PGPR, bacterial cellulose and whey protein isolate. Colloid Surface A. (2017) 522:445-52. doi: 10.1016/j.colsurfa.2017.03.020

39. Wang J, Tan Y, Xu H, Niu S, Yu J. Effect of 2, 2-azobis (2amidinopropane) dihydrochloride oxidized casein on the microstructure and microrheology properties of emulsions. Food Sci Biotechno. (2016) 25:128390. doi: 10.1007/s10068-016-0202-8

40. Li X, Wang X, Liu J, Xu D, Cao Y, Sun B. The effect of unadsorbed proteins on the physiochemical properties of the heteroaggregates of oppositely charged lactoferrin coated lutein droplets and whey protein isolate coated DHA droplets. Food Funct. (2018) 9:3956-64. doi: 10.1039/C8FO00371H

41. Márquez AL, Wagner JR, Palazolo GG. Effects of calcium content and homogenization method on the microstructure, rheology, and stability of emulsions prepared with soybean flour dispersions. Eur J Lipid Sci Tech. (2018) 120:1700500. doi: 10.1002/ejlt.201700500

42. Chihi ML, Mession JL, Sok N, Saurel R. Heat-induced soluble protein aggregates from mixed pea globulins and beta-Lactoglobulin. J Agr Food Chem. (2016) 64:2780-91. doi: 10.1021/acs.jafc.6b00087

43. Roesch R, Corredig M. Heat-induced soy-whey proteins interactions: formation of soluble and insoluble protein complexes. J Agr Food Chem. (2005) 53:3476-82. doi: 10.1021/jf048870d

44. Xu D, Yuan F, Wang X, Li X, Hou Z, Cao Y. The effect of whey protein isolatedextran conjugates on the freeze-thaw stability of oil-in-water emulsions. $J$. Disper. Sci. Technol. (2010) 32:77-83. doi: 10.1080/01932690903546785

Conflict of Interest: The authors declare that the research was conducted in the absence of any commercial or financial relationships that could be construed as a potential conflict of interest.

Copyright $(0) 2020 \mathrm{Xu}$, Zheng, Che, Liu, Yuan, Wang and Cao. This is an open-access article distributed under the terms of the Creative Commons Attribution License (CC $B Y)$. The use, distribution or reproduction in other forums is permitted, provided the original author(s) and the copyright owner(s) are credited and that the original publication in this journal is cited, in accordance with accepted academic practice. No use, distribution or reproduction is permitted which does not comply with these terms. 